\title{
A Study on the Quality Evaluation of English Teaching Based on the Fuzzy Comprehensive Evaluation of Bat Algorithm and Big Data Analysis
}

\author{
Shu Ji $\mathbb{i D}^{1}$ and Sang-Bing Tsai $\mathbb{D}^{2}$ \\ ${ }^{1}$ Department of General Foundation Requisite, Henan College of Transportation, Zhengzhou, Henan 450000, China \\ ${ }^{2}$ Regional Green Economy Development Research Center, School of Business, Wuyi University, Nanping, China
}

Correspondence should be addressed to Shu Ji; jill200403@163.com and Sang-Bing Tsai; sangbing@hotmail.com

Received 10 August 2021; Revised 1 September 2021; Accepted 13 September 2021; Published 14 October 2021

Academic Editor: Weifeng Pan

Copyright (c) 2021 Shu Ji and Sang-Bing Tsai. This is an open access article distributed under the Creative Commons Attribution License, which permits unrestricted use, distribution, and reproduction in any medium, provided the original work is properly cited.

In this paper, the fuzzy comprehensive evaluation model based on the bat algorithm quantifies the qualitative evaluation effectively and provides a feasible and convenient English teaching quality evaluation system by combining quantitative evaluation with objective index data. Firstly, the English teaching quality evaluation model is constructed based on the fuzzy comprehensive evaluation analysis method and the weight values of each factor are calculated; secondly, the three types of data in the model are processed separately. This includes standardizing the data of objective indicators such as students' course grades and weakening the influence of course difficulty on this indicator. The fuzzy comprehensive evaluation model based on the bat algorithm quantifies the qualitative evaluation to make the calculated comprehensive evaluation of English teaching quality more comprehensive and objective; then the comprehensive calculation of English teaching quality evaluation is completed, and the English teaching quality evaluation model is constructed by extracting keywords based on the qualitative evaluation; finally, a runnable English teaching quality evaluation system is designed and implemented. A fuzzy comprehensive evaluation algorithm based on improved bat algorithm optimization is proposed. The algorithm uses the improved fuzzy comprehensive evaluation algorithm to optimize the initial clustering centers and adopts a new objective function to guide the clustering process, thus improving the clustering quality of the fuzzy comprehensive evaluation algorithm. Comparative analysis through models shows that the improved algorithm improves the clustering accuracy to a certain extent when compared with the traditional fuzzy comprehensive evaluation clustering algorithm for analysis. The bat algorithm is one of the stochastic global optimization models. It can take advantage of the group, integrate global search and local search, and achieve rapid convergence. Therefore, it plays an important role in optimizing the evaluation of English teaching quality. This study enriches the theoretical study of English teaching quality evaluation to a certain extent and can play a role in strengthening and improving English teaching quality evaluation at the present stage.

\section{Introduction}

In today's society, computer technology continues to evolve and change with each passing day, and the development cycle continues to shorten. More and more attention is paid to computer technology, and the establishment of corresponding English teaching management systems has enhanced the level of English teaching work. However, some problems are found when the English teaching system is put into use. There is no English teaching quality evaluation function in the system or the English teaching quality evaluation function is not sound enough, the management method of the information about the database adopts the slightly old query and statistics, without using the latest technology, and the characteristics of the database are not effectively designed and developed, which will produce some waste of resources [1,2]. Therefore, a set of English teaching quality evaluation systems that can adapt to the development 
of the times is urgently needed. Good English teaching quality is the top priority of the work task; if you want to survive and develop in society, the cornerstone of English teaching quality must be firmly played, which is the basic task of everyone. If you want to improve the quality of English teaching, you must understand the actual ability of teachers, guide teachers to improve the quality of English teaching according to their specialties, and at the same time, improve their business level, prompted by a more powerful teaching team [3]. Affected by the traditional English teaching quality evaluation model and the guiding ideology of light basic courses and heavy professional courses in higher vocational colleges, a large proportion of higher vocational colleges still use final exam results or English test results to evaluate the effect of English teaching. Summative evaluation is the main and formative evaluation is supplemented. It ignores the developmental changes of various evaluation elements in the teaching process, and it is not conducive to motivating the innovative thinking and personalized development of evaluation objects $[4,5]$.

Building an English teaching quality evaluation system is highly significant research. Researching the English teaching quality evaluation system can help enrich relevant educational theories and form a set of evaluation systems that highlights its characteristics. Secondly, English teaching quality evaluation can scientifically and effectively measure the merits of a course and help administrators to have a systematic understanding of the course English teaching and make decisions. At the same time, school administrators can carry out curriculum reform and promote curriculum construction based on the evaluation results to facilitate the improvement of English teaching quality. The two main aspects of evaluating the quality of teachers' English teaching are teaching and learning [6]. Teaching is the teacher, learning is the students, and students and teachers are interconnected to make up English teaching. Students will have a measure of the teacher's teaching style and level, and students are the direct beneficiaries, so the students' evaluation of the teacher becomes an important evaluation criterion and also the easiest way to get feedback. So a complete and scientific student evaluation system is very important to improve the accuracy and science of student evaluation. In this paper, we analyze and study the current situation of English teaching, existing problems, and English teaching evaluation to find a new focal point for English teaching quality evaluation, create an English teaching quality evaluation atmosphere that keeps pace with the times, fundamentally improve the science, comprehensiveness, and fairness of English teaching evaluation, and then improve the quality of English teaching [7]. The research innovation of the English teaching evaluation mode is also a new promotion of the college curriculum construction, which can provide a theoretical basis and practical proof for the college English teaching authority to develop an English teaching quality evaluation system.

This project aims to design and implement a comprehensive and objective teacher English teaching quality evaluation system for users. Unlike traditional evaluation methods, the system combines qualitative and quantitative evaluation and transforms the qualitative evaluation of evaluation subjects into quantitative evaluation through natural language technology processing; the system will solve the problem of strong subjectivity in the qualitative evaluation and compensate for the problem of incomplete indicators in quantitative evaluation [8]. In addition, the system takes into account the convenience that evaluation subjects can evaluate teachers' English teaching quality across geographical restrictions; meanwhile, English teaching quality managers can easily and quickly see the results of teachers' English teaching quality evaluation and the generated English teaching quality evaluation models. The first part of this paper is the introduction, which discusses the background of the ELT quality evaluation study, clarifies the purpose of ELT evaluation, and explains the theoretical and practical significance of this study. The second part of this paper focuses on analyzing the current situation of English teaching quality evaluation and the problems that exist. The third part of this paper focuses on the research of English teaching quality evaluation based on the fuzzy comprehensive evaluation of the bat algorithm. By studying the English teaching quality evaluation indexes, the fuzzy comprehensive evaluation model of English teaching quality is constructed in combination with the improved bat algorithm, and the evaluation system is also designed in combination with the model. The fourth part of this paper analyzes the research of English teaching quality evaluation. The fifth part of this paper is the conclusion of the study and describes the shortcomings of the study. It is a summary and review of the content of the whole paper and also puts forward a new prospect for future work and research. It should develop a reasonable English teaching management system, focus on the construction of faculty, carefully select supervisors, clarify responsibilities, create a reasonable and sound English teaching evaluation system, better serve to improve the quality of English teaching, and lay a solid foundation for the long-term development, stable development, and innovative development of the institution.

\section{Related Work}

The study of English teaching quality evaluation is not a new issue; scholars at home and abroad have already ventured into this field and have made some valuable research results. The evaluation of English teaching quality emerged with the emergence of education and is developed with the development of education. So far, many evaluation methods have emerged, and the most commonly used methods at present are absolute evaluation method, relative evaluation method, individual difference evaluation method, analytical evaluation method, comprehensive evaluation method, and realistic evaluation method. Yadav A et al. analyzed the teaching quality of some institutions based on fuzzy comprehensive evaluation algorithm and bat decision tree algorithm, using hierarchical analysis technique and data mining technique to evaluate the quality of English teaching [8]. Mashwani et al. studied the English teaching quality evaluation system based on the fuzzy comprehensive evaluation of bat algorithm, which was combined with fuzzy comprehensive evaluation 
technique to realize the input of evaluation data sources, selection of evaluation options, flexible setting of evaluation weights, and setting of evaluation options. Based on data mining technology and bat algorithm [9], Shareh et al. designed and implemented an English teaching quality evaluation system and evaluated the quality of English teaching. English teaching evaluation needs a scientific and complete evaluation system. The main thing is how to plan the evaluation relationship between the two subjects of teaching and learning, that is, the teacher and the students, firstly, the students should have an accurate and scientific collection of evaluation information about the teacher's performance in class, and secondly, it lies in making a good mutual evaluation between teachers [10]. And to link the evaluation of students and teachers together to produce actual results, to concentrate such relevant evaluation methods as summative evaluation, formative evaluation, and preparatory evaluation, and to make them as a whole option of the evaluation system will be more comprehensive [11].

The establishment of formative and summative evaluation systems can be guided by the quality standards of English teaching in education, follow the English teaching standards, conduct English teaching quality evaluation seminars by inviting experts, combine the English level of our students, social needs, and other focus points, and also draw on the questionnaires completed by students and the results of English teaching interviews completed by teachers to clarify the evaluation of each. We can also draw on the results of the English teaching quality evaluation questionnaires completed by students and the English teaching interviews completed by teachers to clarify the elements and indicators of the evaluation, formulate corresponding evaluation criteria and conduct quantitative analysis, and finally form an English teaching quality evaluation system suitable for our college [12]. Huang et al. directly assigned zero weights to the features with less information and then clustered the selected subspaces. However, this method will destroy the integrity of the original data set, which will have an impact on the final clustering results. Educational evaluation should first set goals, and the establishment of established goals can effectively guide the evaluation of English teaching effectiveness, while the evaluation of English teaching effectiveness can promote the educational work toward the ideal goal of English teaching [13]. Ge et al. proposed a generalized entropy fuzzy comprehensive evaluation algorithm based on feature weighting by introducing the entropy constraint term into the objective function of the bat fuzzy comprehensive evaluation algorithm and showed through experiments that the improved algorithm can, to a certain extent, solve the problem of low evaluation quality due to uniform contraction of the comprehensive evaluation algorithm in that the study compares the real situation in the process of English teaching with the ideal goal comparison, which is considered as the actual course of ELT assessment [14]. Rao et al. introduced particle swarm algorithm in the basic bat algorithm and used acceleration factor to control the speed of individuals effectively, and the experimental results showed that the improved algorithm had better searchability and considered that ELT assessment is a process of acquiring and collecting information with clear objectives and systematically, and integrating and analyzing it, and finally assisting decision-makers of ELT management and assessment to make the process of scientific and rational choice among many possible assessment options [15].

The improved bat fuzzy comprehensive evaluation algorithm is applied to the actual English teaching quality evaluation, the English teaching quality evaluation is classified and identified, and a good clustering effect is achieved. The data of the English teaching quality evaluation result is clustered, and in different categories, a comparative analysis of the characteristics of English teaching is carried out to predict the quality of English teaching, which has a certain reference value for the evaluation of English teaching quality [16]. This paper specifies the evaluation of English teaching quality as the object of research and proposes the degree of influence of English teaching quality on schools, by sorting out and summarizing the theories of English teaching quality evaluation, analyzing and studying English teaching quality evaluation indexes, and getting the important factors for being able to influence English teaching quality. In practical terms, the index system of English teaching quality evaluation is designed based on the analysis of English teaching quality theories. The data were processed, suggestions related to the improvement and evaluation methods were made, and expectations were made for the future evaluation of the quality of English teaching in schools. Quantitative evaluation, objective data values, and processing of qualitative evaluation were made $[17,18]$. The quantitative evaluation data collected from the questionnaires were weighted and calculated; the objective data values were standardized to reduce the data differences caused by the difficulty of the courses; the qualitative evaluation data were quantified by the fuzzy comprehensive evaluation model of the bat algorithm, and the quantified data were placed in the evaluation model to participate in the calculation of the comprehensive results of the teachers' English teaching quality evaluation $[19,20]$.

\section{Research on the Quality Evaluation of English Teaching Based on the Fuzzy Comprehensive Evaluation of Bat Algorithm}

3.1. English Teaching Quality Evaluation Index. In English teaching quality evaluation, English teaching quality evaluation should have respective English teaching quality evaluation indexes to reflect the specific evaluation elements of different disciplines, to have better reference and guidance for English teaching. In English teaching, emphasis should be placed on the evaluation of practical English teaching links, distinguishing between the evaluation of theoretical courses and practical training courses, and the evaluation indexes should reflect the course objectives and lecture characteristics of both and the focus of the investigation. As English is a public basic course of liberal arts, the English teaching quality evaluation form should show the course characteristics and specific indicators of evaluation, and if 
there is a lack of scientific and reasonable quantification of indicators and the concept of evaluation is not well defined, it will affect the objective and fair evaluation of English teaching quality to a certain extent. The evaluation of teachers' English teaching process should assess English teaching design, English teaching methods, and English teaching attitudes while focusing on the teachers' ability to teach students' vocational quality and industry English, which is a special feature of English teaching. Finally, in the evaluation of the English teaching effect, the evaluation index of teachers guiding students to participate in English language proficiency competition can be added to enhance the cultivation and practice of students' language proficiency.

In ELT activities, the goal of the scientist is to develop students' five competencies, including motor, attitudinal, intellectual skills, cognitive strategies, and verbal information. These five ELT competencies are also included within the three domains of motor skills domain, cognitive domain, and affective domain. The development of other important aspects such as students' independent thinking and their ability to learn efficiently are highlighted and serve primarily to develop the intellectual aspects of students. Psychology has laid a solid theoretical foundation for the training of students in all aspects, but there are still many problems to be solved if the evaluation of English teaching quality is to be truly realized. The current application of English teaching evaluation in real life has not been popularized, and the main reason for this is the lack of theoretical research support. Therefore, in this process of clarifying educational goals, it is important to avoid using the method of simply applying formulas to educational practice and to take corresponding measures according to their different characteristics, so as not to complicate things and not to deviate from the final formulated educational goals because of the variety of goals.

In the process of ELT quality evaluation, there are three types of ELT quality evaluation, including formative evaluation, preparatory evaluation, and summative evaluation. The ELT process includes many kinds of elements of different nature and ways, which determine the quality of ELT, among which ELT environment, ELT methods, teachers, students, curriculum, and ELT feedback are particularly important, and the conclusions drawn from ELT evaluation of the whole ELT process and the final results of ELT are reliable and credible. Based on the relevant literature, this paper establishes a preliminary English teaching quality evaluation index system based on the ideas and principles of the index system, with 4 primary indexes and 14 secondary indexes, the primary indexes are represented by symbol $A$, and the secondary indexes are represented by symbol $B$. The specific contents are shown in Table 1.

The ELT objectives are the guiding principles of curriculum design, the expectations of educational outcomes, the starting point of the curriculum, and the basis for the design of educational activities. The course content should pay attention to the combination of practice and theory to make its content more practical. The evaluation criteria of whether a teacher's class is well organized, able to highlight key content, and has exciting and engaging arguments are meant to suggest that teachers should focus on stimulating students' thinking and potential. In the classroom, teachers can increase teacher-student interaction, ask questions, organize group discussions, or intersperse some lectures and other activities, all of which can effectively stimulate students' interest in research and lead them to take the initiative to learn, thus improving their independent thinking. An excellent course should focus on the differences in students' research directions, take into account every student as much as possible, and cultivate their creative abilities. An excellent course should focus not only on its goals and processes but also on the final results of teaching English. A good process without a good result is useless for students' development and meaningless for teachers' efforts. Therefore, teachers should be targeted according to the English teaching objectives and students' learning tasks to achieve good English teaching results. Most of the current education focuses on cultivating innovative and application-oriented talents, so teachers should not only start from what students have learned but also expand the textbook knowledge with extracurricular practice to improve the cultivation of innovative quality and research ability.

\subsection{Fuzzy Comprehensive Evaluation Model Based on Im-} proved Bat Algorithm. This paper constructs an English teaching quality evaluation model based on the bat algorithm, and the model contains the processing of quantitative evaluation data, the standardization of objective index data, and the quantification of qualitative evaluation. The left branch is the processing process of each data, and the right branch is the construction process of the English teaching quality evaluation model $[21,22]$. First, we build a hierarchical relationship with related elements. Second, we construct a judgment matrix for the determined level and then check the consistency of the judgment matrix. Finally, we calculate the weight value of each level element. The construction of the element level and the judgment matrix will directly affect the final comprehensive evaluation result. Therefore, these two parts are given by the personnel with professional ability in combination with previous years' experience and existing English teaching quality evaluation methods (Figure 1).

Since there is no available prior knowledge about the population, a random method is generally used to determine the location when initializing the location of the population. This method tends to lead to uneven distribution of bat individuals, which has an impact on the convergence speed of the algorithm. In contrast, the chaotic mapping is ergodic and regular and can meet the randomness requirement of population initialization. Therefore, logistic chaotic mapping is used to initialize the location of the bat population, and the system equation is equation (1), where $\beta$ is the control parameter and $B(t)_{i}$ is the value of the $i$ th chaotic variable after $t$ chaotic mappings.

$$
B(t+1)_{i}=\beta * B(t)_{i} *\left(1-B(t)_{i}\right), \quad i \subseteq[1, N] .
$$

The traditional bat algorithm and other intelligent optimization algorithms, such as the particle swarm algorithm, 
TABLE 1: English teaching quality evaluation index system.

\begin{tabular}{|c|c|c|c|c|}
\hline $\begin{array}{l}\text { Research evaluation } \\
\text { object }\end{array}$ & $\begin{array}{l}\text { First-level } \\
\text { indicator }\end{array}$ & $\begin{array}{l}\text { Meaning of first-level } \\
\text { indicators }\end{array}$ & $\begin{array}{l}\text { Secondary } \\
\text { indicators }\end{array}$ & Meaning of secondary indicators \\
\hline \multirow{7}{*}{$\begin{array}{l}\text { English teaching } \\
\text { quality }\end{array}$} & \multirow{2}{*}{$A$} & \multirow{2}{*}{ Teaching objectives } & $A 1$ & Training goals and teaching plan \\
\hline & & & $A 2$ & Improve learning ability \\
\hline & \multirow[b]{2}{*}{$B$} & \multirow[b]{2}{*}{ Teaching content } & $B 1$ & Subject new theory and practice related \\
\hline & & & $B 2$ & $\begin{array}{l}\text { Focus on key points and teach students by their } \\
\text { aptitude }\end{array}$ \\
\hline & \multirow[b]{2}{*}{$C$} & \multirow[b]{2}{*}{$\begin{array}{l}\text { Teaching methods and } \\
\text { methods }\end{array}$} & $C 1$ & Independent thinking and flexible approach \\
\hline & & & $C 2$ & $\begin{array}{c}\text { Diversified teaching methods and diverse } \\
\text { assessment methods }\end{array}$ \\
\hline & $D$ & Teaching effect & $\begin{array}{l}D 1 \\
D 2\end{array}$ & $\begin{array}{l}\text { Teaching goals and research capabilities } \\
\text { Innovation quality and academic quality }\end{array}$ \\
\hline
\end{tabular}

are prone to prematurely approaching the local optimum individual leading to falling into the local optimum, and the traditional bat algorithm and the particle swarm algorithm operate with similar mechanisms, therefore, a nonlinear dynamic adaptive speed weighting factor is added to the bat algorithm, and the computational equation is equation (2), where $B_{i}$ is the function fitness value of the current individual, $\operatorname{avg}(B)$ is the mean value of $B_{i}, \min (B)$ is the minimum value of $B_{i}, \max (w)$ is the maximum value of $w$, and $\min (w)$ is the minimum value of $w$.

$$
w=\max \left(\min (w)+\frac{(\max (w)-\min (w)) *\left(B_{i}-\min (B)\right)}{\operatorname{avg}(B)-\min (B)}, \max (w)\right)
$$

For each sample in a dataset, the different role of the point on the clustering result depends on the density of samples around it. If more samples are gathered around, the point contributes more to the clustering result and the weight is higher; conversely, the point contributes less to the clustering result and the weight is smaller. The proximity of each sample point to each other is calculated by equation (3), where $\beta$ is a constant and $i=1,2, \ldots \ldots, N$.

$$
f(x)_{i}=\sum_{j=1}^{N} \ln \left(\beta *\left(x_{i}-x_{j}\right)^{2}\right) .
$$

The coefficient of variation is a statistic that measures the degree of variation of each attribute in the data distribution. The greater the variance of the attribute values, the greater the variance of the attribute values, the greater the weight of the attribute that better reflects the gap between the data objects. Let a set of data $X=\left\{x_{1}, x_{2} \ldots . . x_{n}\right\}$, the equation for calculating its coefficient of variation $f(x)$ in

$$
f(x)=\frac{\sqrt{(1 /(n+1)) \sum_{i=1}^{n}\left(x_{i}-x_{i-1}\right)^{2}}}{\left(\sum_{i=1}^{n} x_{i}\right) / n} .
$$

The weight equation of each attribute factor is in equation (5), where $N$ denotes the number of attributes.

$$
w_{i}=f(x) / \sum_{i=1}^{N} f\left(x_{i}\right)
$$

Based on the fuzzy comprehensive evaluation algorithm, the sample weights $u_{i}$ and attribute weights $w_{i}$ are introduced into the objective function of the fuzzy comprehensive evaluation algorithm optimized based on the improved bat algorithm. The objective function of the improved fuzzy comprehensive evaluation algorithm is

$$
H(u, w)=\sum_{i=1}^{n} u_{i}+\sum_{i=1}^{N} w_{i}\left(x_{i}-u_{i}\right)^{2}
$$

The iterative update formula for the fuzzy affiliation degree $u_{i}$ is obtained as

$$
u_{i}=\sum_{i=1}^{N} w i\left(x_{i}-u_{i-1}\right)^{1 / m-1}
$$

It is sometimes necessary to understand the degree of affiliation of each factor to "excellent, good, moderate, pass, and to be improved," not only in general terms. This can be achieved through the degree analysis of each factor. The equation for calculating the degree coefficient of each factor is shown in equation (8). Here, $E(i)$ denotes the degree coefficient of the ith factor; $H(i)$ denotes the degree of affiliation of the ith factor to each grade in the judgment matrix $H . M(i)$ denotes the transposition matrix of the grade parameters.

$$
E(i)=\left(\sum_{i=1}^{n} H(i) * M(i)\right)^{-1}
$$

3.3. English Teaching Quality Evaluation Design. The singularity and formality of the structure of English teaching entity space have led to the quality of English teaching entity space in schools not effectively meeting the needs of English teaching quality of English majors in applied undergraduate institutions. Therefore, it is necessary to optimize the English 


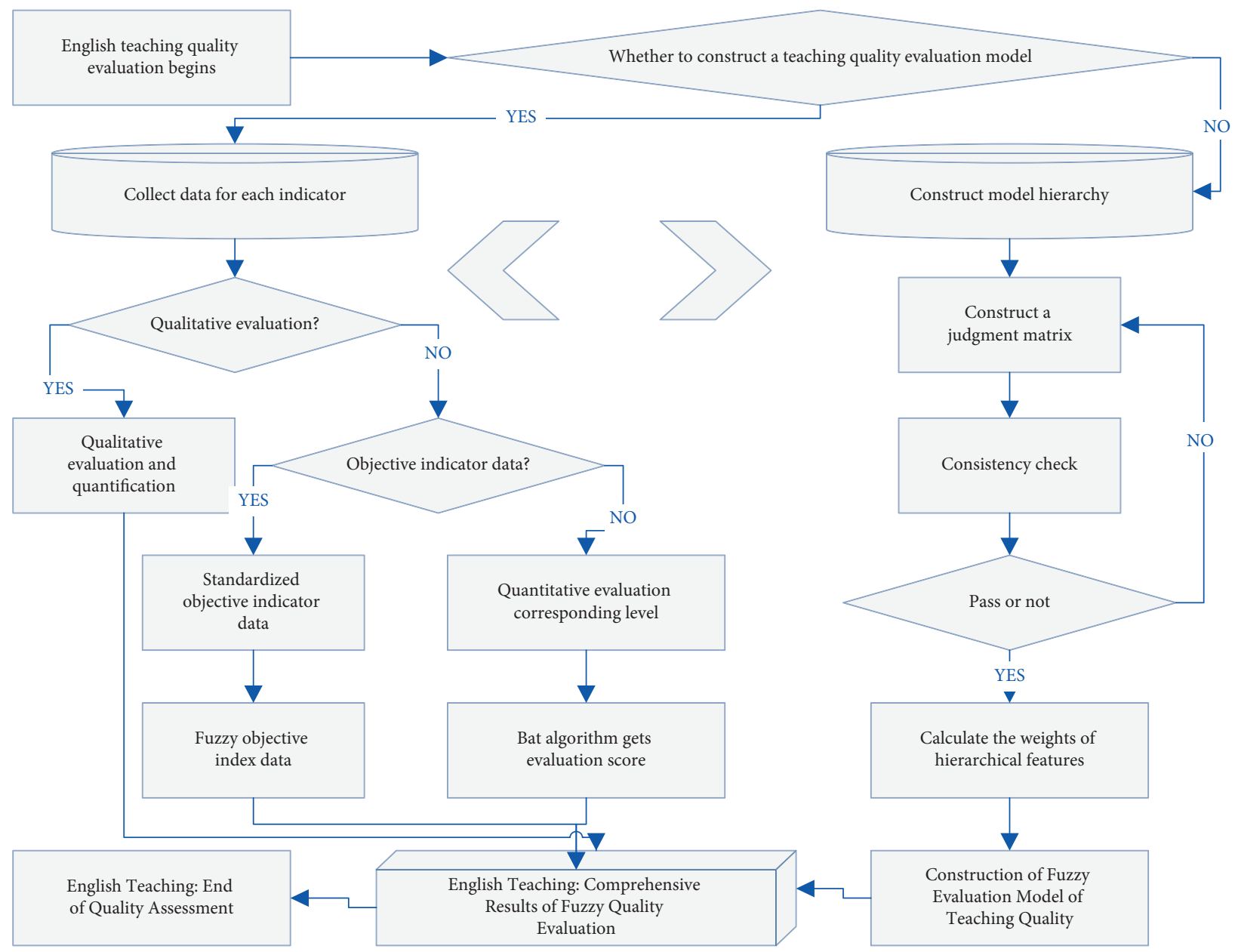

FIGURE 1: Flowchart of English teaching quality evaluation model construction.

teaching physical space and increase the support for the English teaching physical space. This includes providing Modern English teaching tools and differentiated English teaching places, providing a facilitated English learning center, and regularly inviting foreign master teachers to lecture on campus to broaden students' horizons and improve their professionalism. When the physical space for English teaching is optimized, students will have a relaxed and pleasant learning environment for learning English knowledge, which in turn will help improve their selfawareness and self-confidence in learning. Therefore, it is necessary to accelerate the optimization of the physical space of English teaching, including the physical space of English teaching, the physical space of learning, and the physical space generated by external faculty.

Facing the monotonous and limited supply of software infrastructure will inevitably lead to the failure of the school software infrastructure services to reflect the characteristics of the training of applied talents. If the software infrastructure fails to meet the style of applied talent cultivation, it will become an important fundamental factor that restricts the quality improvement of English teaching in English majors in applied undergraduate institutions since English majors in applied undergraduate institutions require schools to provide a flexible and versatile software infrastructure. Compared with research universities, English majors in applied undergraduate institutions place more emphasis on application and thus require more flexible and variable systems, management, and services. Therefore, schools should adopt a more flexible and changeable software infrastructure, including application-oriented training programs for English majors, specialized departments and institutions in charge of English majors with applicationoriented programs, diverse corporate internship opportunities, corporate research, and learning experiences that are more in line with the majors, and timely and effective handling of student opinions.

The system adopts a three-layer architecture design of display layer, business layer, and data layer. The display layer is the layer closest to the user, mainly providing content display and user interaction functions. The display layer adopts the Bootstrap framework to plant the front-end pages and display the business logic processing results returned by the business layer. The business layer mainly provides corresponding functions for different user roles (students, teachers, supervisors, and faculty leaders) and contains services such as permission control of the system, quantification of qualitative evaluation of English teaching quality, 
calculation of English teaching quality evaluation, and the portrait of teachers' English teaching. In this system, the business layer as a whole adopts the YAF framework as the basic framework of the system, and the display layer communicates with the business layer using the standard. The data layer mainly includes data storage and data update.

The main function of the English education quality evaluation management module is that when a user logs in as a student, teacher, or expert, he or she is first prompted to define the evaluation target, and the system predefines rules for the user to score and evaluate the evaluated object. Students, teachers, or experts score the evaluated teachers, and each student and expert can only rate a teacher once. Students can only evaluate the English teaching quality of their current teachers, and experts need to have rich English teaching experience in the courses taught by the evaluated teachers. According to the evaluation algorithm in Chapter 3 , the fuzzy relationship matrix of the first-level indicators is obtained, and then, the comprehensive evaluation result of the first-level indicators is obtained by the principle of direct matrix multiplication, the first-level evaluation matrix is further obtained, the final comprehensive evaluation result is the product of the weights and the first-level evaluation matrix, and the evaluation result is submitted to the system.

\section{Analysis of Results}

4.1. Analysis of English Teaching Quality Evaluation Indexes. Firstly, the weight and importance ranking analysis of the criterion level indicators and their subordinate indicators are performed, followed by the description of the indicator affiliation dimensions derived from the fuzzy comprehensive evaluation. From the fuzzy comprehensive evaluation method, the indicator affiliation dimension of each indicator is known. Among them, the scores of English teaching content, teacher quality, and English teaching quality feedback are in the good range, while the scores of English teaching resources and English teaching effect are in the poor range; in particular, the score of English teaching effect is relatively low. The scores of English teaching resources and English teaching effectiveness are in the "average" range, especially the low score of English teaching effectiveness. According to the first-level calculation results of the fuzzy comprehensive evaluation method, the expert group believes that $10.43 \%$ of English teaching resources may be "best", $40.86 \%$ may be "good", $45.21 \%$ may be "general", 3.49\% may be "poor", and $0.56 \%$ may be "worst" (Figure 2).

The second level of a comprehensive evaluation is to analyze the affiliation degree of the indicator layer. Since there is only one indicator in the indicator layer, which is the quality of English teaching, we do not analyze the percentage of the indicator but directly enter into the fuzzy comprehensive evaluation analysis. From the results of the second level evaluation, we can see that the quality of English teaching in the target layer has an $8.41 \%$ possibility of being best, $42.65 \%$ possibility of being good, $39.68 \%$ possibility of being general, and $8.68 \%$ possibility of being best. There are a $7.56 \%$ probability of being poor and a $1.21 \%$ probability of being worst. According to the principle of maximum affiliation, we believe that the target layer as a whole is in a "better" state. The analysis results are shown in Figure 3.

By innovating English teaching methods and enriching English teaching tools, students' curiosity can be mobilized. With the renewal of educational philosophy, the main body of classroom English teaching is gradually converted from teachers to students, encouraging students to take the initiative to find knowledge and teachers to play a guiding role. Therefore, elementary school English teachers should improve the fun of classroom English teaching while ensuring the order of the classroom, using games, situational performances, and other activities to stimulate students' curiosity, and cultivate their interest in learning English, encourage students to speak English boldly, let students participate in English teaching, not just a knowledge recipient, strengthen students' English listening, speaking, reading, and writing skills, and get rid of the embarrassing situation of "dumb" English. Secondly, we encourage students to realize their main position in classroom learning. When their self-confidence is improved, their interest in learning will be stronger and their learning effect will be better. Education is not a one-way street, and the interaction between teachers and students will realize the mutual growth of English teaching. Teachers' active exploration will stimulate students' learning initiative, students' positive thinking will be motivated and praised by teachers, and the interaction between the subjects of English teaching enhances each other's confidence and helps to improve the quality of English teaching in a breakthrough way. In addition, classroom English teaching should be combined with Modern English teaching methods, under the premise that the necessary facilities are available; for example, the application of multimedia means will help students' image thinking through sound and image to be enhanced. However, the Old English teaching methods and single-mode are one of the main factors limiting the quality of English education in my elementary school, and this disadvantage can be solved directly from the teachers' point of view, in terms of both education costs and education expenses which are extremely low, and can be "copied" and promoted by teachers.

\subsection{Fuzzy Comprehensive Evaluation Algorithm Model} Analysis. To verify the performance of the improved bat algorithm proposed in this paper, the bat algorithm, GAKBAT algorithm, and the algorithm in this paper were compared separately, and the Iris and Wine datasets in the UCI database were selected for 20 experiments each. The results of the comparison of the clustering centers of the three algorithms after running on the Iris dataset are shown in Figure 4. From Figure 4, it can be seen that the error sum of squares between the clustering centers obtained by the improved algorithm and the actual clustering centers on the Iris dataset is 0.015 , which is the closest to the actual centers (Figure 4).

To further verify the clustering quality of this paper's algorithm, the three algorithms are experimentally compared in terms of correct rate and running time, and the 


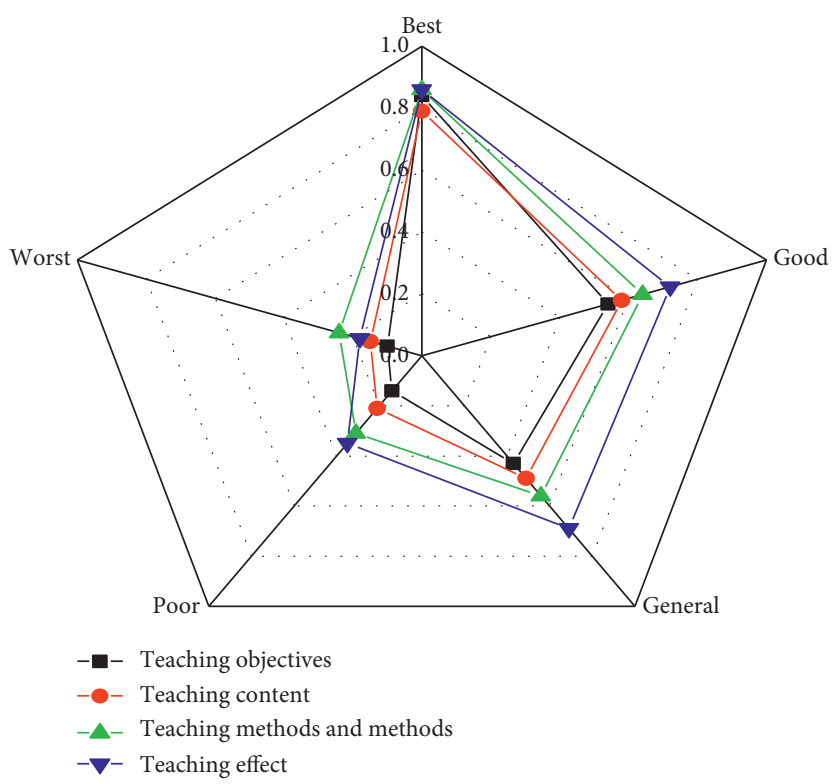

Figure 2: Criterion level indicator affiliation.

results are shown in Figure 5. From Figure 5, the correct rate of this algorithm is $96 \%$ on the Iris dataset, while the correct rate of the traditional bat algorithm is $89.33 \%$, which is lower than that of this algorithm; the correct rate of the GAKBAT algorithm is $92.67 \%$, which is higher than that of the traditional bat algorithm but lower than that of this algorithm. In the Wine data set, the highest correct rate of this algorithm is $94.94 \%$, while the correct rates of the traditional bat algorithm and GAKFCM algorithm are $68.54 \%$ and $82 \%$, respectively, which are lower than the correct rates of this algorithm. Secondly, comparing the running time of the algorithms, the running time consumption of this algorithm on the Iris and Wine data sets is slightly higher than that of the traditional bat algorithm due to the addition of the improved bat algorithm's optimization process but less than that of the GAKFCM algorithm. In summary, the algorithm in this paper achieves high clustering accuracy with reasonable time consumption.

To visualize the clustering effect, the real distribution results of the first two-dimensional sample points of the Iris dataset are selected. Figure 6 shows the clustering results obtained by the traditional bat algorithm, GAKBAT algorithm, and the algorithm in this paper, and it can be seen that the clustering results in this paper are better (Figures 5 and 6).

\subsection{Analysis of English Teaching Quality Evaluation Design.} The results of the resource utilization test are shown in Figure 7(a). During the whole scenario test, the CPU resource usage of the test server is $200 \mathrm{MB}$ to $300 \mathrm{MB}$, and the performance is balanced during the whole test. The response time test results are shown in Figure 7(b). From Figure 7(b), it can be seen that there were two relatively large fluctuations (load reaching maximum concurrency) throughout the test, but overall, the maximum response time for the server to process the submit operation was 6.9 seconds, which included 3 seconds of thinking time. It indicates that the system functions designed and implemented in this article are relatively complete and meet the initial requirements (Figure 7).

In the experiment, we collected 100 samples and used the algorithm of this paper to conduct an experimental study on the data of each of the five attributes (namely, "English teaching ability," "English teaching method," "English teaching content," "English teaching effect," "English teaching attitude," and "English teaching effectiveness") in these samples. The number of evaluation processes $k=3$, and the results of the evaluation analysis are shown in Figure 8. Therefore, the English teaching management should pay more attention to the effect of English teaching while strengthening the supervision and management of English teaching implementation, and from the previous classroom English teaching evaluation system, it is known that the effect of English teaching requires students to master the content taught by teachers, accomplish the English teaching objectives, achieve corresponding English teaching tasks, and, after English teaching activities, inspire students to think, improve student performance and learning efficiency, and help students learn to deal with problems. Therefore, in the future, teachers should pay more attention to the inspiration of students in the management of English teaching, and in the new progress of the subject knowledge, to combine theory and practice to better train students' problem-solving ability (Figure 8).

To improve the quality evaluation of English teaching, the college also needs to invest a lot of money: to hire experts and teachers inside and outside the university to supervise and evaluate English teaching, to increase research funds for English teaching quality evaluation-related topics and projects, to provide funds to encourage teachers to participate in English teaching quality evaluation-related training and conferences, to learn advanced English teaching quality 


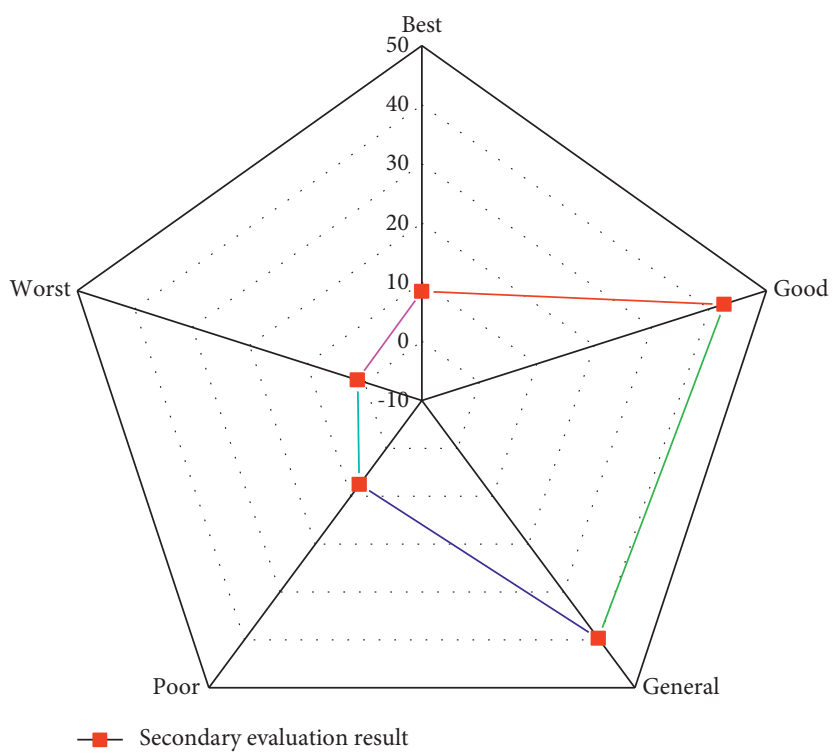

Figure 3: Target layer affiliation.

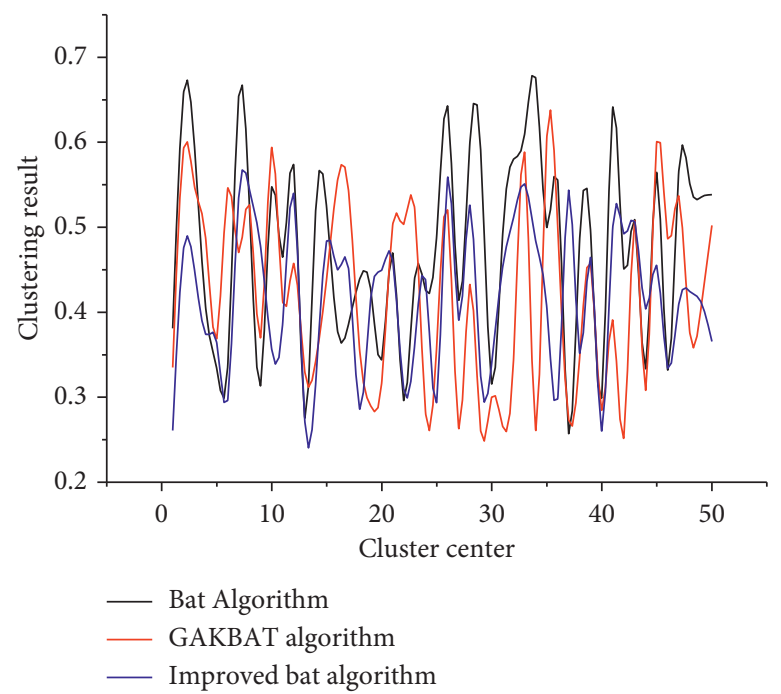

Figure 4: Comparison of clustering centers.

evaluation models, and to make continuous innovation in the process of English teaching. The university will also provide funding to encourage teachers to participate in training and conferences on ELT quality assessment, learn from advanced ELT quality assessment models, and make continuous innovative attempts in the ELT process. In terms of English teaching hardware, it is also necessary to increase the construction and maintenance costs of various platforms for online and offline evaluation data collection and collation, such as big data and cloud computing, and other information technology means, to ensure the long-term tracking and analysis of English teaching quality evaluation data. Reasonable and effective provision of financial guarantee is a practical guarantee for the improvement of English teaching quality evaluation. The final evaluators of the quality evaluation of English teaching in institutions are the society and employers. The vocational nature of English education determines that it must meet the needs of the market. Therefore, the college can also provide the following guarantees: regularly carry out surveys of institutional interns, graduates, and employers, and, through various forms of follow-up visits by departments and employers, understand through multiple channels whether the students' English education level has met the students' job requirements. Whether it has met the needs of enterprises, and whether it can meet the students' subsequent work. The program is a way to strengthen the social force's influence on the quality of English teaching. This is where the influence of social forces on English teaching quality evaluation is strengthened, and where the realistic basis for institutions to implement English teaching reform and improve English teaching quality evaluation lies. 

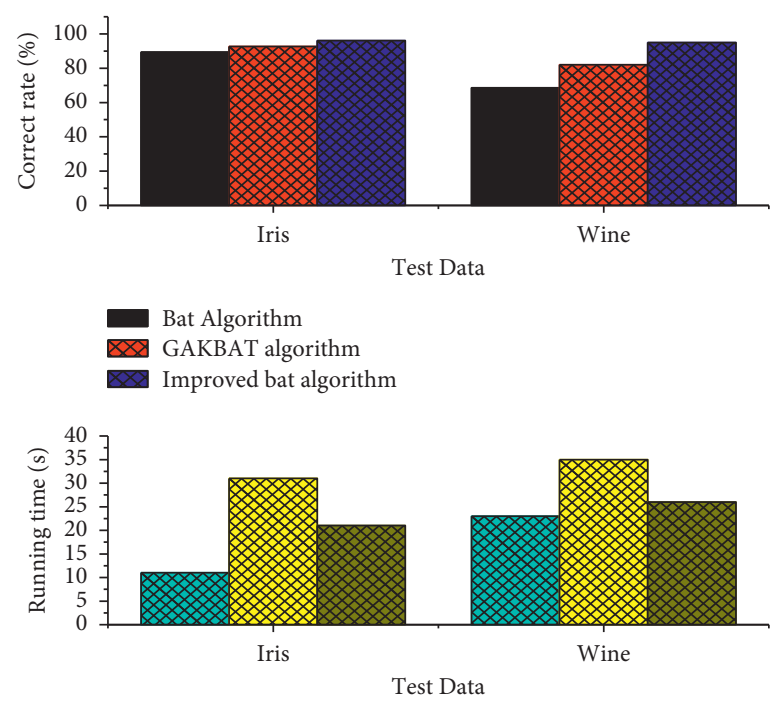

Bat Algorithm

WX GAKBAT algorithm

EX Improved bat algorithm

Figure 5: Comparison of the three algorithms in terms of correct clustering rate and running time.

(1) Bat Algorithm clustering results

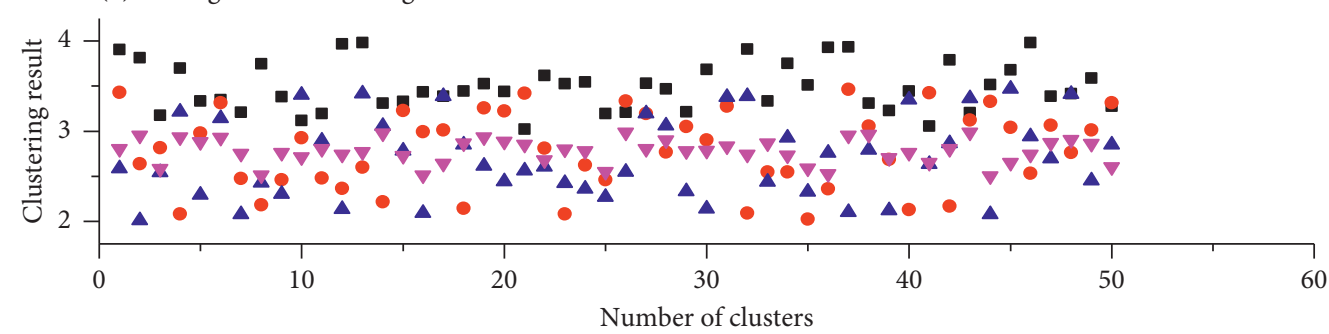

- Cluster 1

- Cluster 2

\. Cluster 3

$\checkmark$ Cluster 4

(2) GAKBAT algorithm clustering results

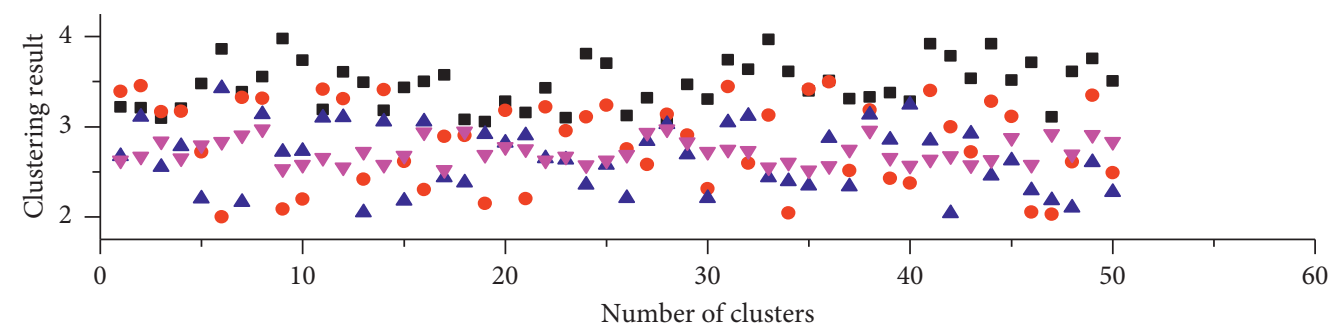

- Cluster 1

- Cluster 3

- Cluster 2

$$
\checkmark \text { Cluster } 4
$$

(3) Improved bat algorithm clustering results

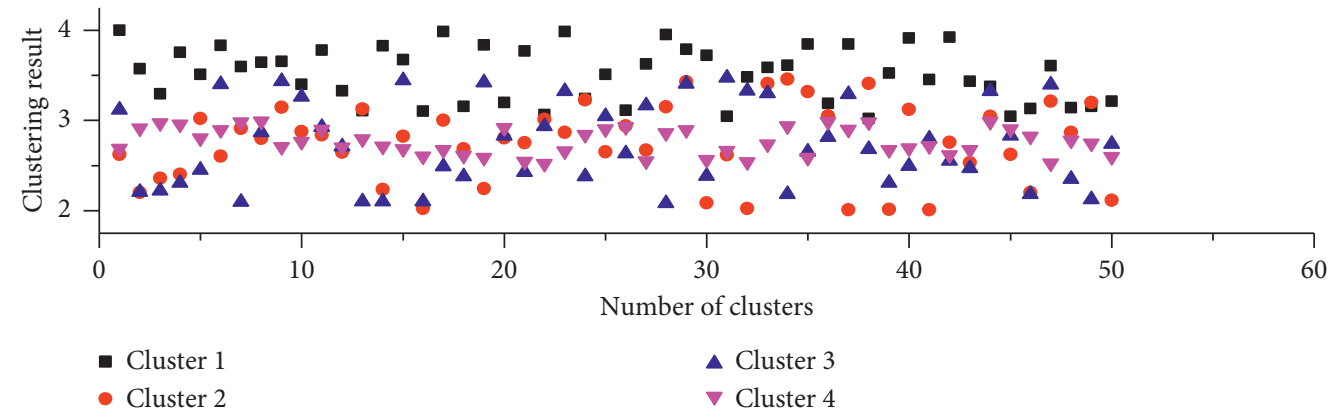

FIGURE 6: Algorithm clustering results. 


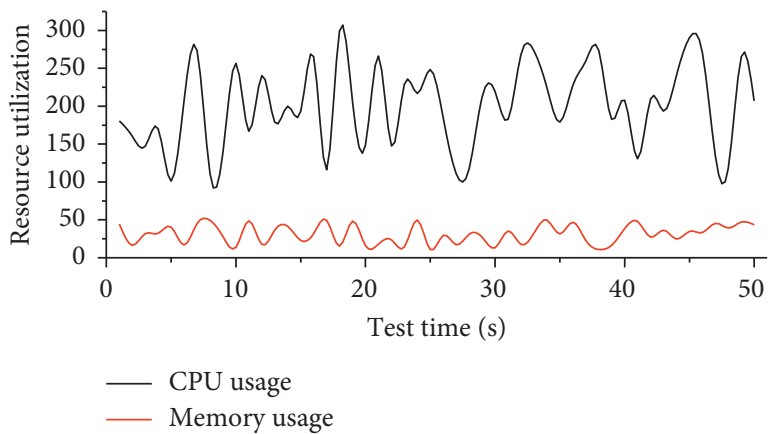

(a)

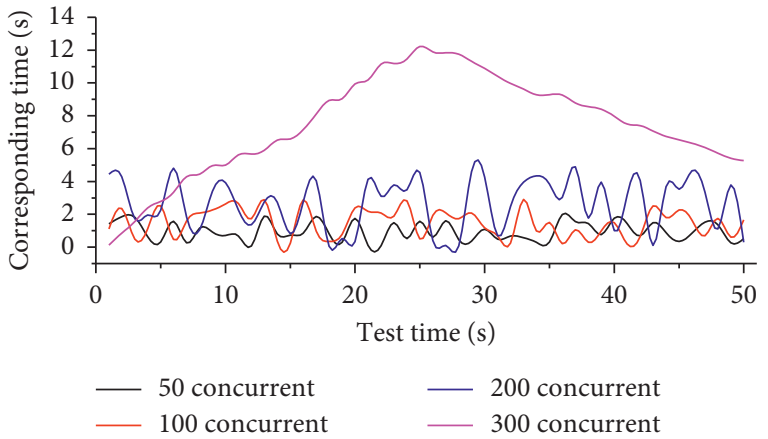

(b)

FiguRE 7: Resource usage and response time test results. (a) Resource usage test results. (b) Response time test results.
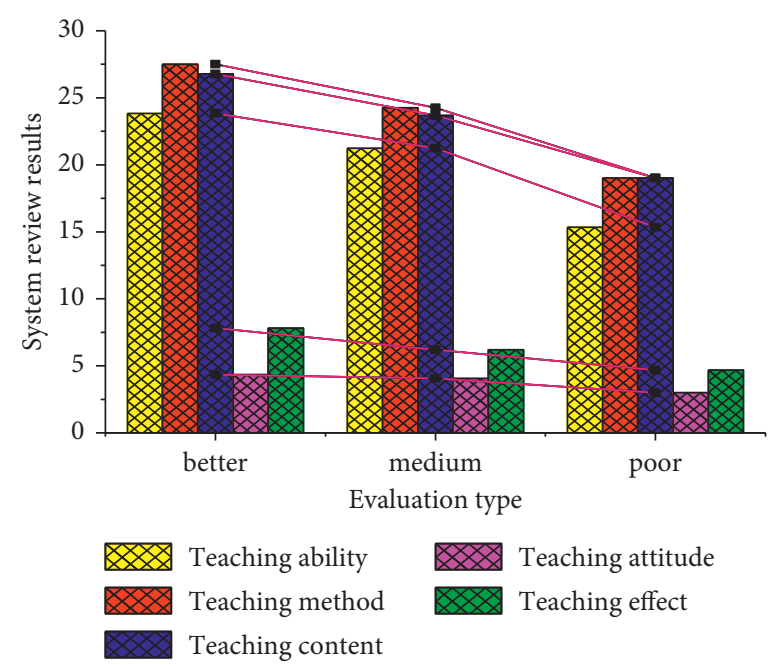

FIGURE 8: English teaching quality system evaluation results.

\section{Conclusion}

The evaluation of English teaching quality is an important help to cultivate talents, implement teaching reform, improve the quality of English teaching, and has a long-term and stable supporting role for theoretical research on English teaching. However, through the current analysis of English teaching quality and students' self-evaluation of the questionnaire, it is found that student's English language ability and pragmatic ability are unevenly developed, and the English teaching of English and vocational skills are not closely integrated. The bat algorithm was improved to address the shortcomings of the bat algorithm, and the experimental comparison with the traditional bat algorithm was conducted. The results showed that the improved algorithm improved the solution accuracy and convergence speed to a certain extent, which verified the feasibility of the improved algorithm. Then, to address the shortcomings of the fuzzy comprehensive evaluation algorithm, a fuzzy comprehensive evaluation algorithm optimized based on the improved bat algorithm is proposed, which optimizes the way of initial center selection and integrates the influence of different samples and attributes on the clustering results. The qualitative evaluation is classified by the fuzzy comprehensive evaluation model of the bat algorithm, the classified reviews corresponding to the rating criteria are quantified, and the quantified evaluations are incorporated into the evaluation model for calculation, so that the final evaluation results are more comprehensive and objective. Experimental simulations of the improved algorithm were conducted, and the clustering results obtained were more accurate. Finally, the improved fuzzy comprehensive evaluation algorithm is applied to the English teaching quality evaluation dataset, and the experimental results show that the improved algorithm can effectively deal with the problems on the evaluation of English teaching quality and provide a certain reference for the evaluation of English teaching quality. The innovation point of this paper is to quantify the users' qualitative evaluation of teachers' English teaching quality using the fuzzy comprehensive evaluation model of the selfbat algorithm. And the quantitative evaluation, qualitative evaluation, and objective data values such as students' course grades are combined to get the results of teachers' English teaching quality evaluation. The quantitative indexes in this paper are rather crude, and only the qualitative evaluation is quantified. In the process of English teaching, there are still 
many quantifiable indicators. The graduation requirement indicator points can be incorporated into the quantitative system later.

\section{Data Availability}

All information is included within the paper.

\section{Conflicts of Interest}

The authors declare no conflicts of interest.

\section{References}

[1] Y. Zou and H. Zhou, "Effect evaluation of small claim procedure based on fuzzy comprehensive evaluation," Journal of Interdisciplinary Mathematics, vol. 21, no. 4, pp. 837-848, 2018.

[2] W. H. Bangyal, J. Ahmad, and H. T. Rauf, “Optimization of neural network using improved bat algorithm for data classification," Journal of Medical Imaging and Health Informatics, vol. 9, no. 4, pp. 670-681, 2019.

[3] S. Asghari and N. J. Navimipour, "Nature inspired metaheuristic algorithms for solving the service composition problem in the cloud environments," International Journal of Communication Systems, vol. 31, no. 12, p. e3708, 2018.

[4] R. Ramesh and V. Saravanan, "Proportion frequency occurrence count with bat algorithm (FOCBA) for rule optimization and mining of proportion equivalence fuzzy constraint class association rules (PEFCARs)," Periodicals of Engineering and Natural Sciences, vol. 6, no. 1, pp. 305-325, 2018.

[5] D. Gao, Y. Liu, and Z. Guo, "A study on optimization of CBM water drainage by well-test deconvolution in the early development stage," Water, vol. 10, no. 7, 2018.

[6] Z. L. Yang, N. Islam, Y. Shi, K. Venkatachalam, and L. Huang, "The evolution of interindustry technology linkage topics and its analysis framework in 3D printing technology," IEEE Transactions on Engineering Management, vol. 99, 2021.

[7] F. Hemasian-Etefagh and F. Safi-Esfahani, "Dynamic scheduling applying new population grouping of whales meta-heuristic in cloud computing," The Journal of Supercomputing, vol. 75, no. 10, pp. 6386-6450, 2019.

[8] A. Yadav and D. K. Vishwakarma, "A comparative study on bio-inspired algorithms for sentiment analysis," Cluster Computing, vol. 23, no. 4, pp. 2969-2989, 2020.

[9] W. K. Mashwani, A. Hamdi, M. Asif Jan, A. Göktaş, and F. Khan, "Large-scale global optimization based on hybrid swarm intelligence algorithm," Journal of Intelligent and Fuzzy Systems, vol. 39, no. 1, pp. 1257-1275, 2020.

[10] M. B. Shareh, S. H. Bargh, A. A. R. Hosseinabadi, and A. Slowik, "An improved bat optimization algorithm to solve the tasks scheduling problem in open shop," Neural Computing \& Applications, vol. 33, no. 5, pp. 1559-1573, 2021.

[11] V. Ravuri and S. Vasundra, "Moth-flame optimization-bat optimization: map-reduce framework for big data clustering using the moth-flame bat optimization and sparse fuzzy C-means," Big Data, vol. 8, no. 3, pp. 203-217, 2020.

[12] M. M. Öztürk, "A bat-inspired algorithm for prioritizing test cases," Vietnam Journal of Computer Science, vol. 5, no. 1, pp. 45-57, 2018.

[13] L. Huang, K. Zhang, W. Hu, and C. Li, “Trajectory optimisation design of robot based on artificial intelligence algorithm," International Journal of Wireless and Mobile Computing, vol. 16, no. 1, pp. 35-40, 2019.

[14] D. Ge, X. Wang, and J. Liu, "A teaching quality evaluation model for preschool teachers based on deep learning," International Journal of Emerging Technologies in Learning (iJET), vol. 16, no. 3, pp. 127-143, 2021.

[15] C. Rao, Y. He, and X. Wang, "Comprehensive evaluation of non-waste cities based on two-tuple mixed correlation degree," International Journal of Fuzzy Systems, vol. 23, no. 2, pp. 369-391, 2021.

[16] M. Choi, H. Kim, B. Han, N. Xu, and K. M. Lee, "Channel attention is all you need for video frame interpolation," Proceedings of the AAAI Conference on Artificial Intelligence, vol. 34, no. 7, pp. 10663-10671, 2020.

[17] D. Das, S. Jaypuria, D. K. Pratihar, and G. G. Roy, "Weld optimisation," Science and Technology of Welding \& Joining, vol. 26, no. 3, pp. 181-195, 2021.

[18] H. Zhang and Y. Cui, "A model combining a Bayesian network with a modified genetic algorithm for green supplier selection," Simulation, vol. 95, no. 12, pp. 1165-1183, 2019.

[19] Z. Yang, W. Zhang, F. Yuan, and N. Islam, "Measuring topic network centrality for identifying technology and technological development in online communities," Technological Forecasting and Social Change, vol. 167, Article ID 120673, 2021.

[20] T. Grubljesic, P. S. Coelho, and J. Jaklic, "The shift to socioorganizational drivers of business intelligence and analytics acceptance," Journal of Organizational and End User Computing, vol. 31, no. 2, pp. 37-64, 2019.

[21] L. Z. Zhang, M. Mouritsen, and J. R. Miller, "Role of perceived value in acceptance of "bring your own device" policy," Journal of Organizational and End User Computing, vol. 31, no. 2, pp. 65-82, 2019.

[22] A. Shahri, M. Hosseini, K. Phalp, J. Taylor, and R. Ali, "How to engineer gamification," Journal of Organizational and End User Computing, vol. 31, no. 1, pp. 39-60, 2019. 